\title{
Design of cefaclor monohydrate containing nanoparticles with extended antibacterial effect by nano-spray dryer: A nanoenglobing study
}

\author{
A. Alper ÖZTÜRK $1 *$ (D), Abdurrahman AYGÜL 2 (D) \\ 1 Department of Pharmaceutical Technology, Faculty of Pharmacy, Anadolu University, Eskişehir, Turkey. \\ 2 Department of Pharmaceutical Microbiology, Faculty of Pharmacy, Çukurova University, Adana, Turkey. \\ * Corresponding Author. E-mail: aaozturk@anadolu.edu.tr (A.A.Ö.); Tel. +90-222-335 05 80/37 31.
}

Received: 26 September 2019 / Revised: 02 December 2019/ Accepted: 07 December 2019

\begin{abstract}
Spray drying is an important method used in pharmaceutical product manufacturing for many years. The nano-spray dryer developed in recent years provides ultrafine powders at nanoscale and high product yields. In this study, which was aimed at prolonged release in oral use, nanoparticles-(NPs) were obtained by nanoenglobation of cefaclor monohydrate-(CEF) with Eudragit RS 100-(ERS) with the help of nano-spray drying method. The particle size (PS) of the blank formulation was $186 \mathrm{~nm}$ whereas PSs of CEF containing NPs were between 328 and $389 \mathrm{~nm}$. The average PDI of all NP formulations were below 0.4 and all prepared NPs had a positive ZP value. The encapsulation efficiency values were a range of 78-84 \%. In vitro release studies of NPs showed extended-release up to 24 hours after the first 3 hours of burst effect. The results showed that the release kinetics were fitted to the Korsmeyer-Peppas model. As a result, it was found that all pharmaceutical technology analysis results were affected by the solid concentration ratio in the feed dispersion. Antibacterial activity of NP formulations was determined by microdilution method. After minimum inhibitory concentration (MIC) determination, time-dependent activity for NP-2 was investigated by the time-kill method. MIC value for NP-2 was 4-fold lower than MIC value of CEF for Staphylococcus aureus and Escherichia coli. No growth was observed for both bacteria with NP-2 during 18 hours incubation in the time-kill method. As a result, prolonged antibiotic release and long-term antibacterial activity were obtained by NP-2, the optimum formulation of our study.
\end{abstract}

KEYWORDS: Cefaclor monohydrate; nano spray drying; nanoenglobing; nanoparticle; antibacterial activity.

\section{INTRODUCTION}

The development of a new drug molecule is not only time-consuming and expensive but also a chain of operations that often fails. However, enhancing the bioavailability, targeting, efficacy or safety of the currently used drugs in the clinic by various methods may be a more effective way of using these drugs in the clinic. Many strategies such as personalized drug therapy, nanoparticle-based drug delivery systems, drug conjugates, therapeutic drug monitoring, stimulant-sensitive targeted therapy have been extensively studied by the investigators [1]. Nanoparticles (NPs) of biodegradable / biocompatible polymers are widely used for controlled and targeted delivery of various drugs. NPs having the drug in a polymeric matrix have excellent clinical benefits, such as reducing the frequency of dosing, increased ease and acceptance by patients and the ability to target the drug to specific sites resulting in high efficacy [2].

There are many approaches for producing NPs such as salting-out, solvent evaporation, supercritical fluid technology, micro-emulsion, mini emulsion, surfactant-free emulsion, interface polymerization, etc. [3]. Apart from these methods, one of the methods commonly used in NP production is spray drying. Spray drying is an excellent technique that quickly removes solvent from a system and provides particles of various different properties that can be specially designed [4]. Spray drying permits optimum temperature conditions suitable for heat-sensitive biopharmaceutical compounds; is an important drying technology that is simple, very fast, reproducible and scalable. Widely used in food, chemical, and pharmaceutical industries [5]. Spray drying technique enables the conversion of feed from a fluid state into dried particulate form by spraying the feed into a hot drying medium. The feed can be a dispersion, suspension, emulsion and mostly used as a solution. Dried particle can be in the form of powder, granule or agglomerate devolving on the chemical and physical

How to cite this article: Öztürk AA, Aygül A. Design of cefaclor monohydrate containing nanoparticles with extended antibacterial effect by nano-spray dryer: A nanoenglobing study. J Res Pharm. 2020; 24(1): 100-111. 
properties of the feed, the dryer design. [6]. Powder samples obtained after drying by conventional spray drying apparatus are generally heterogeneous and have a high particle size (PS). With the conventional spraydrying device, the powder yield is generally low on a laboratory scale. The power of the Büchi Nano Spray Dryer B-90 lies in its vibration mesh spray technology, creating tiny droplets in a size range of a smaller order of magnitude than in traditional spray dryers [7]. Many polymers with natural or synthetic origin are used in the production of NPs. One of the synthetic ones is Eudragit RS 100 (ERS) [8]. ERS is a co-polymer of poly (ethyl acrylate, methyl-methacrylate, and chloro-trimethyl-ammonio-ethyl methacrylate). ERS contains 4.5$6.8 \%$ of quaternary ammonium groups. These quaternary ammonium groups provide a positive charge to ERS [9]. Nanoenglobing is similar to nanoencapsulation, but a solid material is embedded in another solid or liquid product. For the nanoenglobing method; A nano-dispersion is created from a solid product and a matrix material. This suspension is then sprayed into small droplets. The matrix material causes agglomeration or coating of the suspended particles, resulting in a nanocomposite or NPs [5].

Cephalosporins are an important class of antibiotics commonly prescribed in inpatient and community settings for their clinical use in a number of infectious diseases. Only 1-3\% of the population has cephalosporin allergy. This rate is quite low compared to other antibiotic groups [10]. Cephalosporins can be administered orally and parenterally. They are rapidly distributed in biological systems and have a half-life ranging from 0.25 to 9 hours [11]. Cefaclor monohydrate (CEF) is an orally administered semi-synthetic cephalosporin which is frequently prescribed. In normal subjects without an antimicrobial disease, the serum half-life varies between 0.6 and 0.9 hours. The plasma half-life of this molecule is 2.3 to 2.8 hours [11]. Despite the optimum therapeutic effect of $\mathrm{CEF}$, the pharmaceutical form in need is prolonged release.

The oral route is the important expedient route for drug administration. The maintenance of plasma concentration of drug within the therapeutic index is really crucial for effective disease treatment. Oral sustained release products provide several lucrative advantages over conventional dosage forms by maximizing the pharmacokinetic and pharmacodynamic traits of drugs. Sustained release dosage forms provide temporal and spatial control over drug release which cannot be achieved by conventional or immediate release dosage forms [12].

In this study, CEF loaded ERS NPs for oral application were prepared using Büchi Nano Spray Dryer B-90 and characterized. Büchi B-90 Nano Spray Dryer used in this study is able to produce stable, small NPs and to obtain high yields with small spray volumes. The effects of the feed dispersion composition on the NP properties were investigated and detailed characterizations were made to all formulations. Following the selection of the optimum formulation, antibacterial activity against Staphylococcus aureus ATCC 29213 and Escherichia coli ATCC 29522 was determined by microdilution and time-kill method.

\section{RESULT AND DISCUSSION}

\subsection{Preparation of nanoparticles}

There are important parameters to be considered when making NP production by spray drying. In the nano-spray dryer system, unlike standard spray drying apparatus characterized by a pneumatic nozzle; The droplets of liquid feed are produced by a thin, stainless steel membrane of a pulsating piezoelectric system. The membrane has holes of different sizes (spray mesh: 4.0, 5.5 or $7.0 \mu \mathrm{m}$ ) and an ultrasonic frequency vibrates the membrane to deliver precisely sized droplets to the drying zone at high speed. The submicron PS region is typically reached when using a $4.0 \mu \mathrm{m}$ spray mesh [5]. In this study, $4.0 \mu \mathrm{m}$ spray mesh was used because our aim is to obtain particles in nanoscale. Another important factor is the choice of solvent to which the polymer and drug are dissolved and/or suspended. CEF is known as a water-soluble drug that dissolves at a rate of $0.21 \mathrm{mg} / \mathrm{mL}[13,14]$. Compared to water, organic solvents generate slightly smaller droplets due to their lower surface tension, viscosity and density [5]. Therefore, based on the literature, we have used a feed suspension, not a feed solution, for spray drying. This technique is referred to as 'nanoenglobing' in the literature [15]. In our study, two different ratios of CEF were used in the formulations (NP-1 \& NP-2) for comparison. The importance of this difference has been discussed in detail.

\subsection{Characterization of nanoparticles in terms of pharmaceutical technology}

\subsubsection{Particle size, polydispersity index and zeta potential}

The PS, PDI and ZP results of NPs measured by Zetasizer Nano ZS are presented in Table 1. All data obtained from three independent experiments were expressed as the mean diameter and standard deviation (Mean \pm SD) values. The PS obtained in the blank formulation was $186.7 \mathrm{~nm}$, while the PS in the CEF loaded 
NPs was in the range of 328.2-389.1 nm. In mathematical terms, the PS of NP-1 increased almost 2-fold compared to the blank formulation, whereas in the NP-2 coded formulation this value was more than 2-fold. During preparation, the polymeric solution of NP-1 had a solid concentration of $75 \mathrm{mg}$, while the NP-2 contained $150 \mathrm{mg}$ of solid. It is evident from the PS results that the presence of solid concentration in the feed solution dramatically increased the PS. It is frequently encountered in the literature and the argument is that the presence or increase of the solid concentration in the feed solution leads to an increase in PS. As a result, PS results are consistent with the literature $[16,17,18]$.

Table 1. Particle size, polydispersity index and zeta potential results.

\begin{tabular}{cccc}
\hline Formulation code & PS & PDI & ZP \\
\hline Blank & $186.7 \pm 9.0$ & $0.3 \pm 0.1$ & $+40.2 \pm 1.7$ \\
NP-1 & $328.2 \pm 12.5$ & $0.4 \pm 0.1$ & $+39.7 \pm 2.3$ \\
NP-2 & $389.1 \pm 11.7$ & $0.4 \pm 0.1$ & $+36.8 \pm 4.1$ \\
\hline
\end{tabular}

${ }^{*}$ Results are given as Mean \pm SD $(n=3)$

PS results were also compared statistically. Statistical differences of formulations are presented in Figure 1. When Blank, NP-1 and NP-2 coded formulations were compared statistically, an extremely significant difference was observed between CEF loaded NP formulations and blank formulation $(p<0.0001)$. When the NP-1 and NP-2 coded formulations were compared statistically, a very significant difference was observed between PSs ( $p$ <.01). Statistical comparison supports PS results and literature information. When the results are examined in general and the spray-dried NP studies intended for oral administration are examined, the results seem appropriate for the intended purposes $[3,6,19]$.

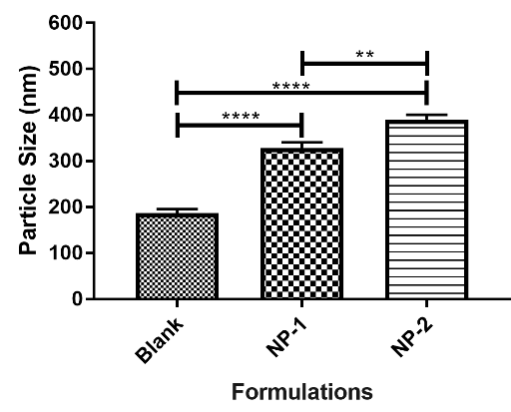

Figure 1. Statistical comparison of particle sizes.

PDI value which defines PS distribution is in the range of 0.01 and 0.7 for monophasic systems; value higher than 0.7 is indicative of a very wide PS distribution and the value close to zero means narrow PS distribution [20]. When the PDI results are discussed in this literature information, it can be said that blank and CEF loaded NP formulations are monodisperse.

The ZP values of blank and CEF loaded formulations are presented in Table 2. The blank formulation and the CEF loaded formulations have almost the same and positive ZP values. Statistically, there was no significant difference between the ZP values of the formulations ( $p>0.05)$. The ZP value is a measure of the electric charge at the surface of the particles indicating the physical stability of colloidal systems. It is recommended that $\mathrm{ZP}$ values between -10 and $+10 \mathrm{mV}$ are considered approximately neutral, while ZPs greater than $+30 \mathrm{mV}$ or less than $-30 \mathrm{mV}$ is considered strongly stable [21]. According to this literature, it can be said that all NPs prepared in this study are highly stable. The NPs prepared with ERS were found to have positive $\mathrm{ZP}$ value owing to the cationic ammonium groups in its structure [6, 22].

\subsubsection{Ultra-performance liquid chromatography (UPLC) conditions}

The UPLC method used in the study was validated for precision, accuracy, and linearity [11]. Linearity was at a concentration range of 5-55 $\mu \mathrm{g}$. $\mathrm{mL}^{-1}$. The method for CEF was precise due to RSD values of $<2 \%$ for repeatability and intermediate precision. Recovery of the method was satisfactory owing to $<2 \%$ RSD value. The CEF showed a linearity of $y=1.5802 x+2.4695\left(\mathrm{r}^{2}=0.9996\right)$, and accuracy of $100.12 \% \pm 0.14,100.62 \% \pm 0.19$ and $98.96 \% \pm 1.16$ (Mean $\% \pm S D$ ) for 15,25 and $35 \mu \mathrm{g} . \mathrm{mL}^{-1}$, respectively $(\mathrm{n}=6)$. The limit of detection (LOD) was 0.587 
$\mu \mathrm{g} . \mathrm{mL}^{-1}$, while the limit of quantitation (LOQ) was $1.780 \mu \mathrm{g} \cdot \mathrm{mL}^{-1}$. The proposed procedure can be used for routine, simultaneous and concurrent determination of CEF [11].

\subsubsection{Encapsulation efficiency (EE\%)}

Drug EE \% of NPs is an important factor in formulations because higher loading leads to a lower number of NPs for a given dose in oral treatment $[23,23]$. EE $\%$ for CEF were $84.4 \pm 2.1 \%$ and $78.5 \pm 1.4 \%$, for NP-1 and NP-2 coded NP formulations, respectively. The NP formulations prepared have appropriate EE\% values that can be candidates for oral administration according to the literature. EE \% of NP-2 was lower than NP-1. As a result, as the amount of active ingredient added during formulation preparation increases, the \% EE decreases. Our results showed that the CEF content on the surface increased with increasing PS. Therefore, the EE\% value is lower in NP-2. A similar situation exists in the literature [24]. EE\% results were also statistically compared. A statistical comparison of the $\mathrm{EE} \%$ results is presented in Figure 2. The result of the statistical comparison is that there is a very significant difference between the two formulations $(p<0.01)$.

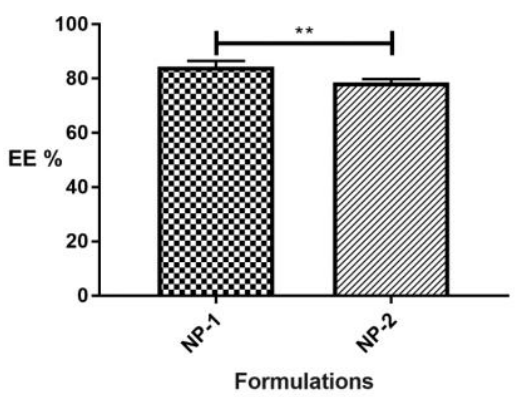

Figure 2. Statistical comparison of encapsulation efficiencies.

\subsubsection{In vitro release and release kinetic evaluation}

In vitro release study is of great importance for formulation development and quality control of the finished product. It is also used to evaluate the bioequivalence of reference and generic products, demonstrate the similarity of pharmaceutical dosage forms, control process and finished product specifications [25]. For this purpose the dialysis bag method was chosen to investigate CEF release from the NP formulation in PBS ( $\mathrm{pH}$ 6.8). In the literature review, it was frequently encountered that the release properties of oral systems were evaluated in PBS ( $\mathrm{pH} 6.8$ ) [20, 26, 27, 28]. In vitro release profile of pure CEF powder and NP formulations are shown in Figure 3. At the end of the $3^{\text {rd }}$ hour, pure CEF powder reached $96.8 \pm 2.4 \%$ (Mean $\pm \mathrm{SD}$ ) cumulative release rate. At the end of the $3^{\text {rd }}$ hour, NP-1 showed drug release at $38.4 \pm 3.4 \%$, while NP-2 showed $51.6 \pm 2.7 \%$ drug release. In vitro release profiles exhibited an initial rapid release in 3 hours which can be attributed to the fraction of drug adsorbed onto the surface of NPs. As it is known from the results of the EE\% study, NP-2 has a higher amount of CEF on the particle surface. Therefore, it can be said that it releases more than NP-1 coded formulation. In another explanation, this can be done as follows. This fast release was related to CEF adsorbed on the NPs surface and/or to the release of the drug encapsulated near to NPs surface [29]. This initial rapid release for all formulations was followed by an extended release pattern owing to the polymeric matrix.

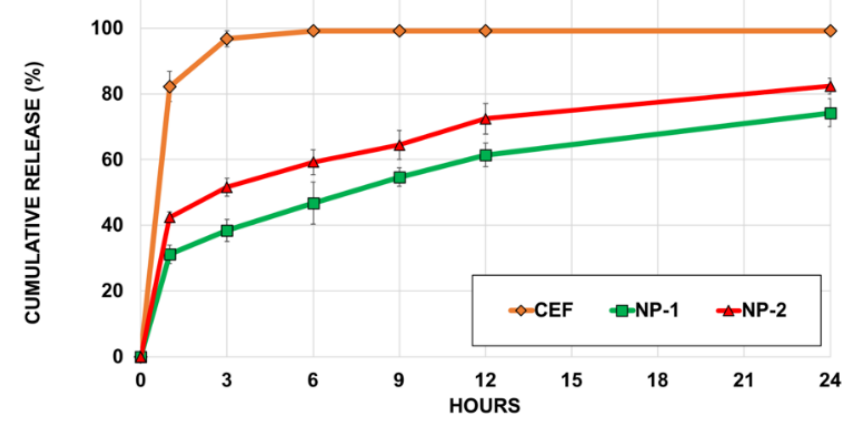

Figure 3. In vitro release profile of pure CEF and NP formulations. 
Fitting in vitro release profiles to mathematical models which describes drug release as a function of time gives valuable data about the in vivo release behavior of optimal delivery system [30]. After obtaining the release profiles, data were transferred to the DDSolver program to determine the four most important and popular criteria: coefficient of determination (Rsqr, $\mathrm{R}^{2}$, or COD), adjusted coefficient of determination (Rsqr_adj or $\mathrm{R}^{2}$ adjusted), Akaike Information Criterion (AIC), Model Selection Criterion (MSC) [20]. It has been shown in many studies that these criteria are used to select the correct release kinetics [20,31]. In most studies, $\mathrm{R}^{2}$ has been reported to be the most important criterion for model selection [32, 33, 34, 35]. The highest $\mathrm{R}^{2}$, $\mathrm{R}^{2}$ adjusted and MSC values and the lowest AIC values were used for evaluating for several models. Kinetic modeling of CEF release from NPs is shown in Table 2. When the results obtained according to DDSolver criteria are examined; release kinetics of all formulations were fitted to Korsmeyer-Peppas model. KorsmeyerPeppas model indicated that drug release followed a combination of diffusion as well as erosion mechanisms [8]. The $n$ values of 0.280 and 0.212 for NP- 1 and NP-2 coded NP formulation, respectively. If $n$ is equal or smaller than 0.45, drug release depends on Fickian diffusion. For $n$ values between 0.45 and 0.85 the drug release occurs through a Non-Fickian diffusion mechanism and for values of $n$ equals to 0.85 the transport occurs by swelling [20]. According to this information, CEF release from NPs prepared in this study can be said to be by Fickian diffusion. Automatic reports from the DDSolver program are presented in Figure 4. This figure shows the predicted and observed release for all NPs and the releases have proven to be compatible with Korsmeyer-Peppas model.

Table 2. Release kinetic modeling of NPs.

\begin{tabular}{cccccc}
\hline & \multicolumn{5}{c}{ Evaluation Criteria } \\
\hline Model and Equation & Code & $\mathbf{R}^{\mathbf{2}}$ & $\mathbf{R}^{2}$ adjusted & AIC & MSC \\
\hline Korsmeyer-Peppas & $\mathbf{N P - 1}$ & 0.995 & 0.994 & 24.259 & 3.879 \\
$\mathbf{F}=\mathbf{k}_{\mathbf{K P}}{ }^{*} \mathbf{t}^{\mathbf{n}}$ & $\mathbf{N P - 2}$ & 0.997 & 0.997 & 21.471 & 4.247 \\
\hline
\end{tabular}

*In Korsmeyer-Peppas model, $\mathbf{F}$ is the fraction (\%) of drug released in time $\mathbf{t}$, $\mathbf{k K r}$ : release constant incorporating structural and geometric characteristics of the drug-dosage form, $\mathbf{n}$ : the diffusional exponent indicating the drug-release mechanism.

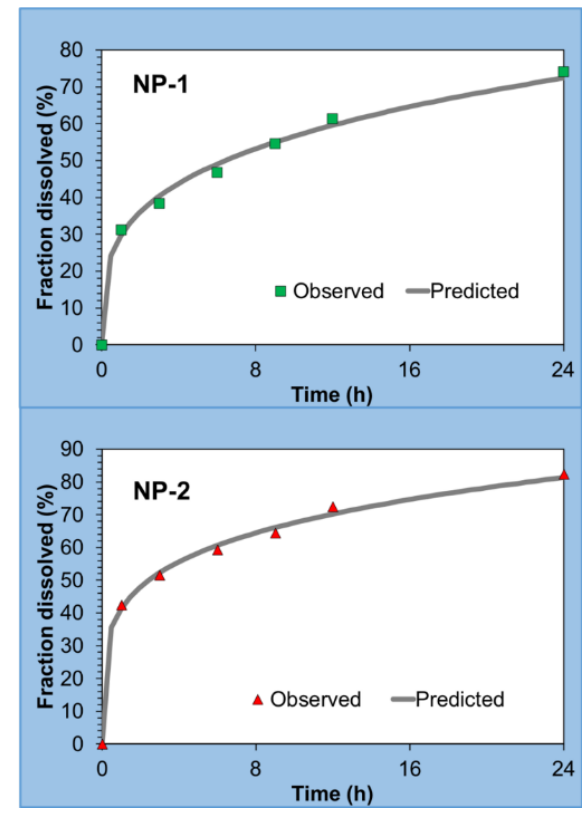

Figure 4. Release kinetic results received automatically from the DDSolver program.

\subsection{Characterization of nanoparticles in terms of pharmaceutical microbiology}

Although the burst release effect in NP formulations is undesirable in some cases, this feature may provide an effective treatment dose at the first dose in oral administration [36]. In the characterization studies of NP formulations prepared in this study in terms of pharmaceutical technology, it was found that more CEF was found on the NP surface of the NP-2 coded formulation and NP-2 coded formulation released about 13.2\% 
more CEF than NP-1 in the first 3 hours. According to this phenomenon, NP-2 was chosen as the optimum formulation and found suitable for antimicrobial tests.

\subsubsection{MIC values of formulations}

CEF is a typical class-2 cephalosporin, generally preferred in upper respiratory tract infections. Its antibacterial spectrum includes Haemophilus influenza, Streptococcus pyogenes, Neisseria gonorrhoeae, Streptococcus pneumoniae, S. aureus and enteric bacteria such as E. coli. For both standard bacterial strain used as a model in our study, the minimum inhibitory concentration (MIC) value of CEF is between $1-4 \mu \mathrm{g} / \mathrm{mL}$. In this respect, quality control requirements were met in terms of antibacterial activity experiments for MIC determination. MIC values of formulations and controls are given in Table 3. According to these results, MIC value of NP-2 was 4-fold lower than MIC value of CEF for both bacteria. No activity was observed with the blank at the concentrations tested as expected.

Table 3. MIC values of formulations and positive/negative controls.

\begin{tabular}{ccc}
\hline \multirow{2}{*}{ Tested formulations } & \multicolumn{2}{c}{ MIC values $(\mu \mathrm{g} / \mathrm{ml})$} \\
\cline { 2 - 3 } & S. aureus ATCC 29213 & E. coli ATCC 29522 \\
\hline NP-2 & 0.25 & 0.5 \\
CEF & 1 & 2 \\
Blank & $64<$ & $64<$ \\
\hline
\end{tabular}

\subsubsection{The superior time-kill activity of $N P-2$}

The time-kill graph of NP-2, CEF solution, blank formulation and growth control are given in Figure 5 and Figure 6 for E. coli and S. aureus, respectively. During 18 hours incubation, no growth was observed for both bacteria with NP-2 at a concentration of one-fourth of MIC value of CEF (for S. aureus $0.25 \mu \mathrm{g} / \mathrm{ml}$, for $E$. coli $0.5 \mu \mathrm{g} / \mathrm{ml}$ ). On the other hand, CEF solution has failed to stop growth at these concentrations and the blank was also not effective as expected. The 18-hour period was not exceeded in this study. The microplate is incubated at $36^{\circ} \mathrm{C}$ with agitation in the microplate reader. Thus, the evaporation occurs rapidly due to shaking. This raises the question of whether there will be changes in the homogeneity of the wells, which initially had the same conditions (the same volume of liquid and the same density of bacteria), due to long periods of incubation. On the other hand, the results obtained by time-kill method in this study made longer incubation unnecessary. Because, $\mathrm{OD}_{600}$ value increased in the first few hours in control groups (Figure 5 \& 6 ), while NP-2 kept growth at the same level for 18 hours.

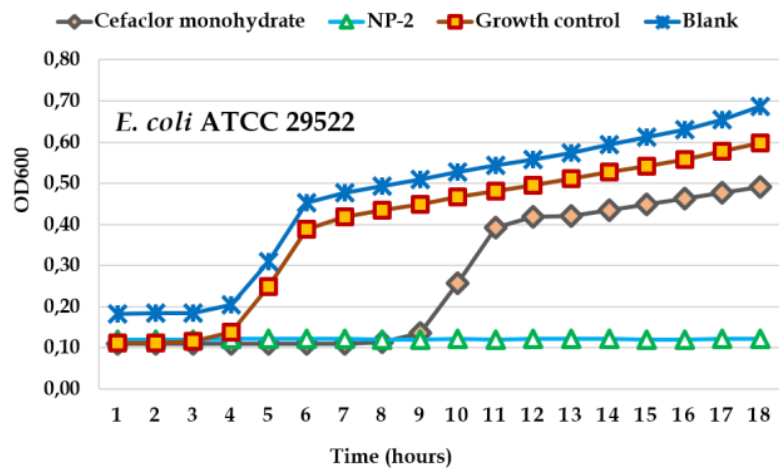

Figure 5. Time-kill assay results for E. coli.

According to the results, designed NP formulations of CEF can effectively increase the antibacterial activity. Besides, as seen in the time-kill activity results, even at low antibiotic concentrations, NP-2 was effective than the control group during the test for longer time periods. Therefore, NP-2 is an ideal formulation for long-term controlled release of CEF.

NPs are widely studied and highly successful instruments at increasing the efficiency of antibiotics. Nanotechnology may be particularly advantageous in treating bacterial infections. Examples include the utilization of NPs in antibacterial coatings for implantable devices and medicinal materials to prevent infection and promote wound healing, in antibiotic delivery systems to treat disease, in bacterial detection systems to 
improve microbial diagnostics, and in vaccines to prevent bacterial infections. Although still not well understood, possible mechanism of increased antibacterial activity by NPs at the molecular level are usually bacterial cell surface-NP interactions [37]. In this context, the most important parameters affecting the optimization of NPs seem to be PS and ZP value of the NP structure. In a study as an example, bacterial surface charges of $S$. aureus and $E$. coli were reported as $-13.1 \mathrm{mV}$ and -2.1 , respectively. It was emphasized in this study that the positive ZP formulations designed were more effective [38]. Similarly, the more effective NP-2 in our study can be explained by the high positive ZP of it. Thus, it can be concluded that the positive charge of the formulation will increase the antibacterial activity by interacting with the negative bacterial surface.

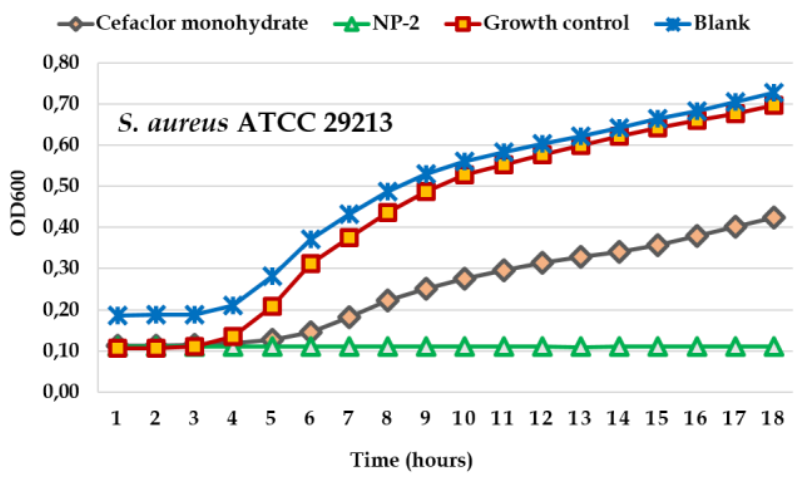

Figure 6. Time-kill assay results for S. aureus.

\section{CONCLUSION}

In this study, NPs were prepared with two different CEF: ERS ratios. We have successfully formulated, CEF containing NPs by nano spray drying method. Detailed characterizations were made to all formulations and obtained results showed that the composition of feed dispersion exerts significant influence on the NP properties. The NP formulation containing less solid CEF (75 mg, NP-1) in the feed solution was found to have low PS and high EE\%, while the NP formulation containing more solid CEF (150 mg, NP-2) had high PS and low EE\%. The EE\% results of NP formulations intended for oral use are highly acceptable. The EE\% ranged from $78-84 \%$ and the EE\% of the NPs decreased as the solid ratio in the feed dispersion increased. The release rates were directly influenced by the EE\%. NP-2 was found to have a higher amount of CEF on the particle surface and therefore showed a more burst release effect than the NP-1 coded formulation in the first 3 hours. All formulations carried out sustained release for up to 24 hours. Korsmeyer-Peppas model was found to be the most suitable model for CEF release from all NP formulations. As a result, it was found that all pharmaceutical technology analysis results were affected by the solid concentration ratio in the feed dispersion.

Antibacterial activity of NP formulations was determined by microdilution method. After determination of MIC values, the time-dependent activity for NP-2 was investigated by the time-kill method. MIC value for NP-2 was 4-fold lower than MIC value of CEF for S. aureus and E. coli. No growth was observed for both bacteria with NP-2 during 18 hours incubation in the time-kill method. As a result, NP-2 coded formulation had increased antibiotic's efficacy and provided long-term activity compared to CEF. Because free drug and NP formulation was investigated using the same concentration of CEF, the improvement in antibacterial activity is probably due to better penetration of the NP formulation into bacterial cells and delivery of CEF to its site of action. The CEF containing NP formulation could also be suitable for drug delivery to phagocytic cells to achieve better treatment of various infections compared with treatment using free CEF. As a total result, prolonged drug release and long-term antibacterial activity were successfully obtained in this study.

\section{MATERIALS AND METHODS}

\subsection{Materials}

CEF is a kind gift from SANOVEL (Istanbul/Turkey). ERS is a kind gift from Evonik Nutrition \& Care $\mathrm{GmbH}$ (Darmstadt/Germany). All other chemicals and reagents used were of pharmaceutical and analytical grade. 


\subsection{Preparation of nanoparticles}

Preparation of NP was carried out using the Nano Spray Dryer B-90 (Büchi Labortechnik AG, Flawil, Switzerland). Nozzle with $4.0 \mu \mathrm{m}$ spray-mesh was used. All feed solutions were filtered through a $0.45 \mu \mathrm{m}$ membrane filter prior to the drying process. The inlet temperature was set at $120^{\circ} \mathrm{C}$ based on preliminary trials and kept constant throughout the process. The airflow rate was $100 \mathrm{~L}^{\mathrm{min}}{ }^{-1}$. The relative spray rate was $100 \%$. Nano spray dryer conditions used in the preparation of formulations are given in Table 4.

Table 4. Nano spray dryer conditions used in the preparation of formulations.

\begin{tabular}{cccc}
\hline Inlet Temperature & Outlet Temperature & Pump Level & Spray Level \\
\hline $120^{\circ} \mathrm{C}$ & $54^{\circ} \mathrm{C}$ & 3 & $100 \%$ \\
\hline
\end{tabular}

For the preparation of the polymeric solution with and without CEF, ERS was dissolved in methanol under a magnetic stirrer at $250 \mathrm{rpm}$ for $2 \mathrm{~h}$ to obtain a clear solution. CEF was added to this clear solution and stirred further for another 30 minutes. Since nanoenglobing was intended, CEF was added directly to the polymeric solution without dissolving in water. Nano Spray Dryer B-90 was conditioned 30 minutes using methanol to obtain the desired levels of spraying, pump level, inlet temperature, outlet temperature, gas flow, and ambient temperature prior to delivering the polymeric solution. Dried NPs were collected in the collecting chamber. Formulation contents were summarized in Table 5.

Table 5. Formulation contents.

\begin{tabular}{cccc}
\hline Formulation code & ERS & CEF & MeOH \\
\hline Blank & $1500 \mathrm{mg}$ & - & $100 \mathrm{~mL}$ \\
NP-1 & $1500 \mathrm{mg}$ & $75 \mathrm{mg}$ & $100 \mathrm{~mL}$ \\
NP-2 & $1500 \mathrm{mg}$ & $150 \mathrm{mg}$ & $100 \mathrm{~mL}$ \\
\hline
\end{tabular}

*Blank: Formulation without adding CEF, ERS: Eudragit RS 100, CEF: Cefaclor monohydrate, MeOH: Methanol.

\subsection{Characterization of nanoparticles in terms of pharmaceutical technology}

\subsubsection{Particle size, polydispersity index and zeta potential}

The PS and PDI of NPs were measured using dynamic light scattering technique (DLS) on the Zetasizer Nano (Zetasizer Nano ZS, Malvern Instruments, Malvern, UK). PS and PDI of NPs were measured by dispersing the formulation in distilled water. $\mathrm{ZP}$ values were determined using the same instrument in a disposable folded capillary zeta cell, at $25^{\circ} \mathrm{C}$ room temperature and diluted with distilled water. For statistical analysis, all samples were measured in triplicate and the average values and standard deviation of the measurements were calculated.

\subsubsection{Ultra-performance liquid chromatography (UPLC) conditions}

The amount of CEF loaded into NPs and in vitro release study of each formulation was performed using UPLC (Agilent Technology 1290 Infinity) with Zorbax Eclipse Plus $C_{18}(1.8 \mu \mathrm{m}, 2.1 \mathrm{~mm} \times 50 \mathrm{~mm})$. In the UPLC system, the mobile phase was methanol: water: $0.1 \mathrm{M}$ acetate buffer $(40: 50: 10 \mathrm{v} / \mathrm{v} / \mathrm{v})$ mixture, the flow rate was $0.25 \mathrm{~mL} \cdot \mathrm{min}^{-1}$, while detection was performed at $265 \mathrm{~nm}$ at $40^{\circ} \mathrm{C}$. Injection volume was $0.5 \mu \mathrm{L}$. The mobile phase was prepared daily, degassed by sonication and filtered through $0.45 \mu \mathrm{m}$ membrane filter before the experiment. The method was validated for precision, accuracy, specificity, and linearity [11].

\subsubsection{Encapsulation efficiency}

In order to determine the amount of CEF in drug-loaded NPs, drug encapsulation efficiency study was performed by a validated UPLC method. Accurately weighed NPs (1 mg) were dispersed in distilled water (1 $\mathrm{mL}$ ), vortexed for $1 \mathrm{~min}$ and centrifuged at $13.000 \mathrm{rpm}$ for $15 \mathrm{~min}$ for the determination of CEF remaining on NP surface (CEF s). The quantity CEF entrapped in NPs was calculated as the difference between the initially added (CEF $t$ ) and the CEFs. Each experiment was repeated three times. The CEF content was expressed as encapsulation efficiency (EE) as in Equation 1 [22]. 


$$
E E \%=\left[\frac{\mathrm{CEFt}-\mathrm{CEFs}}{\mathrm{CEFt}}\right] \times 100
$$

\subsubsection{In vitro release and release kinetic evaluation}

A dialysis membrane method was used to identify release behavior of NPs. In vitro release profiles of CEF were investigated in freshly prepared phosphate buffer saline (PBS, pH 6.8) for a period of 24 hours. Briefly, drug-loaded NPs containing $1 \mathrm{mg}$ CEF were put in dialysis bag (with a molecular cut off 12-14 kD, Sigma) and capped with closures. Bags were immersed into dissolution medium containing $100 \mathrm{~mL}$ PBS at $37 \pm 1^{\circ} \mathrm{C}$ on a water bath using continuous magnetic stirring rate of $100 \mathrm{rpm} .1 \mathrm{~mL}$ of samples were withdrawn at predetermined time intervals and CEF contents in the receptor chamber were determined by UPLC method and release profile of pure CEF was used as a reference for better evaluation of the profiles. Each experiment was repeated three times [39]. To determine the release kinetics, data obtained from in vitro drug release studies in phosphate buffer ( $\mathrm{pH} 6.8$ ) were analyzed by a software program that named DDSolver [40, 41].

\subsection{Characterization of nanoparticles in terms of pharmaceutical microbiology}

\subsubsection{Bacteria, media and formulations}

S. aureus ATCC 29213 and E. coli ATCC 29522 standard strains were used to determine the antibacterial activity of the formulations. The bacteria were maintained at $-20^{\circ} \mathrm{C}$ in Brain Heart Infusion agar with $\% 15$ glycerin and fresh overnight cultures on Nutrient agar were used in the experiments. Mueller-Hinton Broth (MHB) was used for microdilution tests. All media were purchased from BD Biosciences (San Jose, USA). CEF solution and the optimized formulation (NP-2) at $0.512 \mathrm{mg} \cdot \mathrm{mL}^{-1}$ concentration in sterile distilled water were used in antibacterial activity tests. Blank formulation without CEF was also added to the experiments.

\subsubsection{Antibacterial activity testing}

Antibacterial activity of CEF and NP formulations was determined by microdilution method [42]. For this purpose, serial dilutions of NP-2, CEF solution and the blank were performed by using MHB in 96-well U-bottom microplates (Orkim, Turkey). Subsequently, suspensions of freshly cultured bacteria at 0.5 McFarland density were prepared with the help of a densitometer (Grant Instruments, UK) and diluted 1/150 in MHB. These inoculums, adjusted to $10^{6} \mathrm{CFU} / \mathrm{mL}$ density, were added in equal volume over the previously prepared dilutions. Finally, the microplates were incubated at $36 \pm 1^{\circ} \mathrm{C}$ for 24 hours and evaluated visually. The lowest concentration without visible growth in the dilution lines was considered as MIC. Growth control with only bacteria or MHB were also included as positive and negative controls, respectively. All dilutions were performed with double technical replicates.

\subsubsection{Time-Kill assay}

After determination of MIC values, the time-dependent activity NP-2 was investigated by the time-kill method with modifications [43]. Including all control groups, the method was carried out in the same manner as the microdilution method in 96-well F-bottom microplates (Orkim, Turkey). Immediately after the inoculums were added to the serial dilutions of NP-2, the blank, and CEF solution, the microplates were incubated at $36 \pm 1^{\circ} \mathrm{C}$ for 18 hours in a microplate reader (Thermo Fisher Scientific, USA) and read at OD 600 with one-hour intervals. OD values at a given concentration were plotted against time to analyze the data. All dilutions were performed with double technical replicates.

\subsection{Statistical analysis}

Each experiment was carried out three independent times and the data are presented as mean \pm standard deviation (SD). Microsoft Excel and DDSolver were employed for mathematical analysis. All data obtained were evaluated statistically using GraphPad Prism version 7.0. Limit of confidence was selected to be $95 \%$.

Acknowledgements: The authors would like to thank Sanovel (İstanbul, Turkey) for providing a gift sample of Cefaclor monohydrate and Evonik Nutrition \& Care GmbH (Darmstadt/Germany) for providing a gift sample of Eudragit RS 100. 
Author contributions: Concept - AAÖ; Design - AAÖ; Supervision - AAÖ; Resource - AAÖ, AA Materials - AAÖ, AA; Data Collection and/or Processing. AAÖ, AA; Analysis and/or Interpretation - AAÖ, AA; Literature Search AAÖ, AA Writing - AAÖ, AA Critical Reviews - AAÖ, AA.

Conflict of interest statement: The authors declare no conflict of interest.

\section{REFERENCES}

[1] Öztürk-Atar K, Eroğlu H, Çalış S. Novel advances in targeted drug delivery. J Drug Target. 2018; $26(8)$ : 633-642. [CrossRef]

[2] Schulze J, Kuhn S, Hendrikx S, Schulz-Siegmund M, Polte T, Aigner A. Spray-dried nanoparticle-in-microparticle delivery systems (nimds) for gene delivery, comprising polyethylenimine (pei)-based nanoparticles in a poly (vinyl alcohol) matrix. Small. 2018; 14(12): 1-8. [CrossRef]

[3] Öztürk AA, Yenilmez E, Yazan Y. Dexketoprofen trometamol-loaded Eudragit ${ }^{\circledR}$ RL 100 nanoparticle formulation, characterization and release kinetics. ACTA Pharm Sci. 2019; 57(1): 69-84. [CrossRef]

[4] Davis M, Walker G. Recent strategies in spray drying for the enhanced bioavailability of poorly water-soluble drugs. J Control Release. 2018; 269: 110-127. [CrossRef]

[5] Arpagaus C, Collenberg A, Rütti D, Assadpour E, Jafari SM. Nano spray drying for encapsulation of pharmaceuticals. Int J Pharm. 2018; 546(1-2): 194-214. [CrossRef]

[6] Öztürk AA, Yenilmez E, Arslan R, Şenel B, Yazan Y. Dexketoprofen trometamol-loaded Kollidon ${ }^{\circledR}$ SR and Eudragit ${ }^{\circledR}$ RS 100 polymeric nanoparticles: formulation and in vitro-in vivo evaluation. Lat Am J Pharm. 2017; 36(11): $2153-2165$.

[7] Li X, Anton N, Arpagaus C, Belleteix F, Vandamme TF. Nanoparticles by spray drying using innovative new technology: The Büchi Nano Spray Dryer B-90. J Control Release. 2010; 147(2): 304-310. [CrossRef]

[8] Saharan P, Bahmani K, Saharan SP. Preparation, optimization and in vitro evaluation of glipizide nanoparticles integrated with Eudragit RS-100. Pharm Nanotech. 2019; 7(1): 72-85. [CrossRef]

[9] Katara R, Sachdeva S, Majumdar DK. Design, characterization, and evaluation of aceclofenac-loaded Eudragit RS 100 nanoparticulate system for ocular delivery. Pharm Dev Technol. 2019; 24(3): 368-379. [CrossRef]

[10] Chaudhry SB, Veve MP, Wagner JL. Cephalosporins: A focus on side chains and $\beta$-lactam cross-reactivity. Pharmacy. 2019; 7(3): 1-16. [CrossRef]

[11] Öztürk AA, Güven UM. Cefaclor monohydrate loaded microemulsion formulation for topical application: characterization with new developed UPLC method and stability study. J Res Pharm. 2019; 23(3): 426-440. [CrossRef]

[12] Kaur G, Grewal J, Jyoti K, Jain UK, Chandra R, Madan J. Oral controlled and sustained drug delivery systems: Concepts, advances, preclinical, and clinical status. In: Grumezescu Am (Ed). Drug Targeting and Stimuli Sensitive Drug Delivery Systems. William Andrew Publishing-Elsevier, United Kingdom, 2018, pp. 567-626. [CrossRef]

[13] https://www.scbt.com/p/cefaclor-monohydrate-70356-03-5 (accessed August 18, 2019)

[14] https://www.drugbank.ca/salts/DBSALT001804 (accessed August 18, 2019)

[15] Arpagaus C, John P, Collenberg A, Rütti D. Nanocapsules formation by nano spray drying. In: Nanoencapsulation technologies for the food and nutraceutical industries, Academic Press-Elsevier, United Kingdom, 2017, pp. 346-401. [CrossRef]

[16] Lee SH, Heng D, Ng WK, Chan HK, Tan RBH. Nano spray drying: a novel method for preparing protein nanoparticles for protein therapy. Int J Pharm. 2011; 403(1-2): 192-200. [CrossRef]

[17] Baba K, Nishida K. Calpain inhibitor nanocrystals prepared using Nano Spray Dryer B-90. Nanoscale Res Lett. 2012; 7(436): 1-9.

[18] Schmid K, Arpagus C, Friess W. Evaluation of the nano spray dreyer B-90 for pharmaceutical applications. Pharm Dev Technol. 2011; 16: 287-294. [CrossRef]

[19] Elmaskaya A, Öztürk AA, Büyükköroğlu G, Yenilmez E. Spray-dried ketoprofen lysine incorporated plga nanoparticles: formulation, characterization, evaluation and cyctotoxic profile. Ind J Pharm Sci. 2019; 81(4); 640-650.

[20] Öztürk AA, Aygül A, Şenel B. Influence of glyceryl behenate, tripalmitin and stearic acid on the properties of clarithromycin incorporated solid lipid nanoparticles (SLNs): Formulation, characterization, antibacterial activity and cytotoxicity. J Drug Deliv Sci Technol. 2019; 54: 101240. [CrossRef]

[21] Gülsün T, Borna SE, Vural İ, Şahin S. Preparation and characterization of furosemide nanosuspensions. J Drug Deliv Sci Technol. 2018; 45; 93-100. [CrossRef] 
[22] Öztürk AA, Kıyan HT. Treatment of oxidative stress-induced pain and inflammation with dexketoprofen trometamol loaded different molecular weight chitosan nanoparticles: Formulation, characterization and anti-inflammatory activity by using in vivo HET-CAM assay. Microvasc Res. 2020; 128: 103961 [CrossRef]

[23] Şenel B, Öztürk AA. New approaches to tumour therapy with siRNA-decorated and chitosan-modified PLGA nanoparticles. Drug Dev Ind Pharm. 2019; 45(11): 1835-1848. [CrossRef]

[24] Jafari SM, He Y, Bhandari B. Role of powder particle size on the encapsulation efficiency of oils during spray drying. Dry Technol. 2007; 25: 1091-1099. [CrossRef]

[25] Gülsün T, Akdağ Y, Izat N, Öner L, Şahin S. Effect of particle size and surfactant on the solubility, permeability and dissolution characteristics of deferasirox. J Res Pharm. 2019; 23(5): 851-859. [CrossRef]

[26] Öztürk AA, Yurtdaş Kırımlığlu G. Preparation and in vitro characterization of lamivudine loaded nanoparticles prepared by acid and/or ester terminated PLGA for effective oral anti-retroviral therapy. J Res Pharm. 2019; 23(5): 897-913. [CrossRef]

[27] Yılmaz Usta D, Demirtaş Ö, Ökçelik C, Uslu A, Teksin ZŞ. Evaluation of in vitro dissolution characteristics of flurbiprofen, a BCS Class Ila drug. FABAD J Pharm Sci. 2018; 43(2): 117-124.

[28] Chen YD, Liang ZY, Cen YY, Zhang H, Han MG, Tian YQ, Zhang J, Li SJ, Yang DS. Development of oral dispersible tablets containing prednisolone nanoparticles for the management of pediatric asthma. Drug Des Devel Ther. 2015; 9: 5815-5825. [CrossRef]

[29] Çetin M, Atilla A, Kadioglu Y. Formulation and in vitro characterization of Eudragit ${ }^{\circledR}$ L100 and Eudragit ${ }^{\circledR}$ L100PLGA nanoparticles containing diclofenac sodium. AAPS PharmSciTech. 2010; 11(3): 1250-1256. [CrossRef]

[30] Yurtdaş Kırımlığlu G, Özer S, Büyükköroğlu G, Yazan Y. Formulation and in vitro evaluation of moxifloxacin hydrochloride-loaded polymeric nanoparticles for ocular application. Lat Am J Pharm. 2018; 37(9): 1850-1862.

[31] Ergin AD, Sezgin Bayındır Z, Yüksel N. Characterization and optimization of colon targeted S-adenosyl-Lmethionine loaded chitosan nanoparticles. J Res Pharm. 2019; 23(5): 914-926. [CrossRef]

[32] Siafaka P, Okur ME, Ayla Ş, Er S, Çağlar EŞ, Üstündă̆ Okur N. Design and characterization of nanocarriers loaded with levofloxacin for enhanced antimicrobial activity; physicochemical properties, in vitro release and oral acute toxicity. Braz J Pharm Sci. 2019; 55(3): 1-13. [CrossRef]

[33] Aksu B, Yurdasiper A, Ege MA, Üstündağ Okur N, Karasulu HY. Development and comparative evaluation of extended release indomethacin capsules. Afr J Pharm Pharmacol. 2013; 7(30): 2201-2209. [CrossRef]

[34] Üstündağ Okur N, Filippousi M, Okur ME, Ayla Ş, Çağlar EŞ, Yoltaş A, Siafaka PI. A novel approach for skin infections: Controlled release topical mats of poly(lactic acid)/poly(ethylene succinate) blends containing Voriconazole. J Drug Deliv Sci Technol. 2018; 46: 74-86. [CrossRef]

[35] Değim İT, Tuğcu Demiröz F, Tamer İlbasmış S, Acartürk F. Development of controlled release sildenafil formulations for vaginal administration. Drug Deliv. 2008; 15(4): 259-265. [CrossRef]

[36] Huang X, Brazel CS. On the importance and mechanisms of burst release in matrix-controlled drug delivery systems. J Control Release. 2001; 73(2-3): 121-136. [CrossRef]

[37] Wang L, Hu C, Shao L. The antimicrobial activity of nanoparticles: present situation and prospects for the future. Int J Nanomedicine. 2017; 12: 1227-1249. [CrossRef]

[38] Arasoğlu T, Derman S, Mansuroğlu B, Uzunoğlu D, Koçyiğit B, Gümüş B, Acar T, Tuncer B. Preparation, characterization, and enhanced antimicrobial activity: quercetin-loaded PLGA nanoparticles against foodborne pathogens. Turk J Biol. 2017; 41: 127-140. [CrossRef]

[39] Öztürk AA, Martin Banderas L, Cayero Otero MD, Yenilmez E, Yazan Y. New Approach to hypertension treatment: carvediol-loaded PLGA nanoparticles, preparation, in vitro characterization and gastrointestinal stability. Lat Am J Pharm. 2018; 37(9): 1730-1741.

[40] Öztürk AA, Çinar Nİ, Yenilmez E. Development of nano-sized ketoprofen lysine incorporated Eudragit ${ }^{\circledR}$ S100 nanomedicine by double emulsion solvent evaporation and in vitro characterization. J Pharm Pharmacogn Res. 2019; 7(1): 47-58.

[41] Öztürk AA, Martin-Banderas L, Cayero Otero MD, Yenilmez E, Şenel B, Yazan Y. Dexketoprofen trometamol-loaded poly-lactic-co-glycolic acid (PLGA) nanoparticles: preparation, in vitro characterization and cyctotoxity. Trop J Pharm Res. 2019; 18(1): 1-11. [CrossRef]

[42] Clinical and Laboratory Standards Institute (CLSI). Methods for Dilution Antimicrobial Susceptibility Tests for Bacteria That Grow Aerobically, 11th ed. CLSI document M07. 
[43] Clinical and Laboratory Standards Institute (CLSI), Methods for Determining Bactericidal Activity of Antimicrobial Agents. Approved Guideline, CLSI document M26-A.

This is an open access article which is publicly available on our journal's website under Institutional Repository at http://dspace.marmara.edu.tr. 